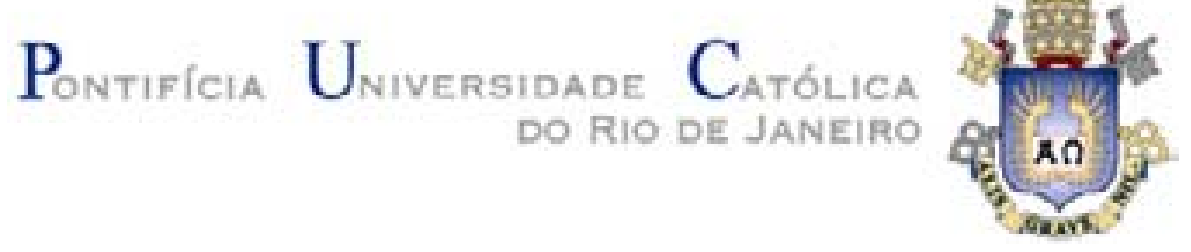

Rafael Duton Alves

Empreendedorismo e o processo de identificação de oportunidades

Dissertação apresentada como requisito parcial para obtenção do título de Mestre pelo Programa de PósGraduação em Administração da PUC-Rio.

Orientador: Prof. José Roberto Gomes da Silva

Rio de Janeiro

Abril de 2005 
Rafael Duton Alves

\title{
Empreendedorismo e o processo de identificação de oportunidades
}

\begin{abstract}
Dissertação apresentada como requisito parcial para obtenção do grau de Mestre pelo Programa de Pós-graduação em Administração de Empresas da PUC-Rio. Aprovada pela Comissão Examinadora abaixo assinada.
\end{abstract}

Prof. José Roberto Gomes da Silva Orientador Departamento de Administração - PUC-Rio

Prof. Antonio José Junqueira Botelho Departamento de Engenharia Industrial - PUC-Rio

Prof. Ursula Wetzel

COPPEAD - UFRJ

Prof. João Pontes Nogueira Vice-Decano de Pós-Graduação do CCS

Rio de Janeiro, 6 de abril de 2005 
Todos os direitos reservados. É proibida a reprodução total ou parcial do trabalho sem autorização da universidade, do autor e do orientador.

\section{Rafael Duton Alves}

Graduou-se em Engenharia da Computação na Pontifícia Universidade Católica do Rio de Janeiro em 2001. Participou da fundação da Empresa Júnior PUC-Rio e em 2000 fundou uma empresa de desenvolvimento de softwares para celulares (nTime Mobile Solutions), atualmente (2005) com 60 funcionários.

Ficha Catalográfica

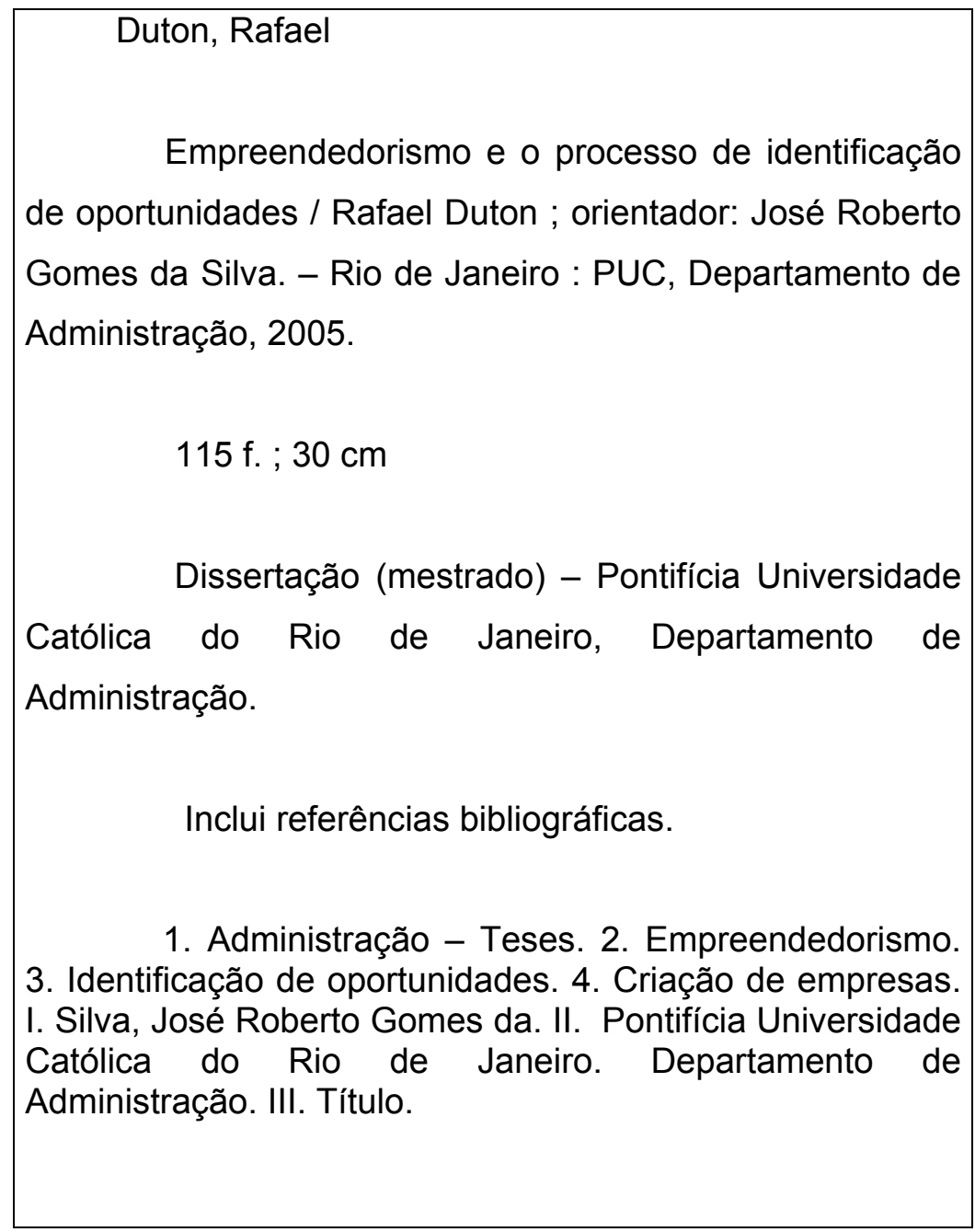

CDD: 658 


\section{Agradecimentos}

A todos que contribuíram ou ajudaram, direta ou indiretamente, para que a realização deste trabalho fosse possível. 


\section{Resumo}

Duton, Rafael. Empreendedorismo e o processo de identificação de oportunidades. Rio de Janeiro, 2005. 115p. Dissertação de Mestrado (Opção profissional) - Departamento de Administração. Pontifícia Universidade Católica do Rio de Janeiro.

O Empreendedorismo é uma manifestação da capacidade humana que tem conquistado a dedicação de estudiosos e pesquisadores da Administração pelo seu impacto social e por sua importância econômica. O Brasil vem se destacando como um dos países de maior nível de Empreendedorismo no mundo, enquanto cresce a percepção de que a atividade empreendedora pode ser um dos fatores decisivos para o desenvolvimento econômico do país. Estudiosos no tema em outros países sugerem que o ponto inicial e principal do processo do Empreendedorismo é a atividade de buscar oportunidades continuamente e de forma criativa. Desta forma, o processo de identificação de oportunidades torna-se uma nova área de importância vital para o estudo do Empreendedorismo. Este estudo revisou os trabalhos sobre o Empreendedorismo divulgados nos meios classificados entre os mais representativos da pesquisa em Administração desenvolvida no país. O objetivo deste trabalho foi compreender como os empreendedores identificam e tratam oportunidades de criação de novos negócios, e para tal, foi necessário determinar e categorizar as fontes de oportunidades disponíveis. Na revisão teórica foram propostos 2 modelos relacionados, sendo um referente às fontes de oportunidades empreendedoras, e outro, ao processo de identificação de oportunidades e criação de empresas. O estudo baseou-se na aplicação de questionário seguido de entrevistas com empreendedores no Brasil, sobre como identificam as oportunidades que geraram seus empreendimentos. Os resultados indicaram que existe uma grande concentração de novos empreendimentos originados por oportunidades detectadas dentro das empresas, assim como outros originados por pesquisas e até mesmo, por uma inspiração do empreendedor.

\section{Palavras-chave}

Empreendedorismo; identificação de oportunidades; criação de empresas 


\section{Abstract}

Duton, Rafael. Entrepreneurshid and opportunities' identification process. Rio de Janeiro, 2005. 115p. M.Sc. Dissertation - Departamento de Administração. Pontifícia Universidade Católica do Rio de Janeiro.

Entrepreneurship is the manifestation of human ability that has absorbed Business Administration scholars due to its economic importance and its social impact. Brazil has stood out as one of the countries with the highest level of Entrepreneurship in the world, and the perception that the development of entrepreneurial activities can be one of the decisive factors in a country's economic development grows at an ever-increasing rate. Scholars in other countries suggest that the initial and principal point in the Entrepreneurship process is the activity of constantly and creatively seeking new business opportunities. This study reviews works on Entrepreneurship in Brazil, published through the various means classified to be the most representative of the Business Administration research conducted in the country. This study aims to achieve a better understanding of how entrepreneurs who have achieved success in their ventures identify and handle new business opportunities. To accomplish this, the sources of opportunities available had to be identified and categorized. Therefore, in the review of Entrepreneurship theory, 2 models relating to this topic were proposed, one referring to the sources of new business opportunities, and the other referring to the process of identifying opportunities and creating new businesses. The study was based on the application of a questionnaire, followed by interviews with entrepreneurs in Brazil. The results indicate that there is a large concentration of new ventures that derived from opportunities detected inside the companies and others that originated from research, as well as ventures that stemmed from the entrepreneur's inspiration.

\section{Keywords}

Entrepreneurship, opportunities identification, companies' creation 


\section{Sumário}

1. O Problema 12

1.1. Introdução 12

1.2. Objetivos $\quad 15$

1.3. Delimitação do Estudo 16

1.4. Relevância 17

2. Referencial Teórico 19

2.1. O Empreendedorismo 21

2.1.1. Origem, Conceito e Teoria 22

2.1.2. Perfil e Comportamento Empreendedor 26

2.1.3. O processo do Empreendedorismo e seu impacto n economia e no ambiente 30

2.1.4. Identificação de Oportunidades 35

2.1.5 Empreendedorismo Corporativo como Fonte de Identificação de Oportunidades 48

2.2. Desenvolvimento do Empreendedorismo no Brasil 52

3. Metodologia $\quad 57$

3.1. Tipo de Pesquisa $\quad 57$

3.2. Definição do universo e seleção da amostra 60

3.3. Coleta de Dados 62

3.4. Tratamento dos dados 66

3.5. Limitações do Método 68

4. Resultados $\quad 70$

4.1. Característica das Empresas $\quad 70$

4.2. Tipos de fontes de oportunidades 72

4.3. Influência da rede de contatos e experiência prévia 82

4.4. Atividades realizadas após a identificação da oportunidade 83

4.5 Experiência dos Entrevistados 86

4.5.1 Como a oportunidade foi identificada 86

4.5.2 Como ocorre a influência da rede de contatos e da 
experiência prévia

4.5.3 Porque realizar determinadas atividades após a identificação da oportunidade

5. Conclusões

5.1. Teste de validação do modelo de fontes de oportunidades

5.2. Recomendação para futuras pesquisas

6. Referências Bibliográficas

Apêndice

Questionário de Pesquisa

113

Critérios para classificação de potencial de sucesso 


\section{Lista de figuras}

Figura 1 - Modelo: Criação de novos empreendimentos 33

Figura 2 - Processo de Identificação de Oportunidades 38

Figura 3 - Fontes de Oportunidades Empreendedoras 43

Figura 4 - Processo decisório do Empreendedor 65

Figura 5 - Gráfico: influência de fatores na identificação de oportunidades 82 


\section{Lista de tabelas}

Tabela 1 - Focos de estudos de Empreendedorismo 20

Tabela 2 - Características dos Empreendedores 28

Tabela 3 - Composição final da amostra de entrevistados 62

Tabela 4 - Roteiro das Entrevistas $\quad 64$

Tabela 5 - Resultados totalizados: fontes de oportunidades $\quad 74$

Tabela 6 - Resultado geral: atividades relacionadas com a identificação da oportunidade $\quad 74$

Tabela 7 - Resultado geral: atividades relacionadas por grupos de fontes de oportunidades $\quad 75$

Tabela 8 - Empresas de alto potencial: fontes como fator predominante da identificação

Tabela 9 - Empresas de alto potencial: atividades relacionadas à detecção

Tabela 10 - Potencial de geração de empresas de alto potencial por fonte de oportunidade

Tabela 11 - Empresas de alto potencial: principais atividades relacionadas à detecção

Tabela 12 - Resultado Geral: quantidade de atividades relacionadas após a identificação 


\section{Lista de quadros}

Quadro 1 - Taxonomia do Processo de Geração de Oportunidades 46

Quadro 2 - Diferenciação da Descoberta, Invenção e Inovação 56

Quadro 3 - Quantidade de empresas por ramo de atuação 71

Quadro 4 - Modelo dos grupos de fontes de oportunidades e suas atividades relacionadas 73

Quadro 5 - Freqüência das atividades realizadas após a identificação da oportunidade 